\title{
Drug and Alcohol Abuse Prevention Education in Selected Secondary Schools in Zambia: Policy Guidelines used
}

\author{
Isaac Masiye ${ }^{1}$, Daniel Ndhlovu ${ }^{2}$ \\ ${ }^{1,2}$ University of Zambia, School of Education, Lusaka. Zambia
}

\begin{abstract}
Drug and alcohol abuse is a growing social and public health problem among secondary school learners in Zambia. The purpose of this article was to establish drug and alcohol abuse prevention policy guidelines used in selected secondary schools. It is an extract from one of the objectives of a PhD study. The background of the study emanates from the fact that despite escalating incidences of drug and alcohol abuse among school-going children, little was known concerning prevention policies used in Zambia's secondary schools. The study adopted a descriptive survey research design to collect, analyze and interpret both quantitative and qualitative data. A total number of five hundred and fourteen (514) respondents participated in the study. Using questionnaires, quantitative data was collected from learners and teachers and analyzed using the statistical package for social sciences (SPSS) to generate tables, graphs and percentages. Semi-structured interview and focus group discussion guides were used to collect qualitative data from Head Teachers, District Education Board Secretaries (DEBS), Drug Enforcement Commission (DEC) officers and learners, In addition, document analysis checklist was also used. Qualitative data was analyzed using thematic analysis. Thus, major themes were drawn for easy descriptions. The study found that there were no specific documents on drug and alcohol prevention policy in all the secondary schools. The elements of drug prevention policy guidelines used were in the general school rules and were punitive in nature as opposed to educational. On the basis of the study findings it is recommended that school drug policies should focus more on educational and remedial measures rather than on punitive measures.
\end{abstract}

Keywords: Drug abuse, Alcohol abuse, Prevention policies, Secondary schools

\section{INTRODUCTION}

\subsection{Background}

Drug and alcohol abuse is one of the major social and public health concerns worldwide. It poses a huge burden on health care systems(Wyler, 2012), and impedes educational achievements of young people. Therefore, its prevention is critical to the sustainability of not only good public health system but also economic and educational development of the country.

In Zambia, drug and alcohol abuse prevention activities have been executed mainly by three different kinds of organisations. These are the Government Ministries/Agencies, Non-Governmental Organisations and religious organisations. The Ministry of General Education (MoGE), Ministry of Health (MoH), Drug Enforcement Commission (DEC) and other Non-governmental organizations (NGOs) and Faith-Based Organizations (FBOs) have been conducting drug and alcohol abuse prevention education in schools. This is because there is evidence that schools provide a good natural setting for implementation of drug abuse prevention programmes and activities (Botvin, 2006). Dunne and Somerset (2004) adds that schools are in a prime position to increase awareness and challenge attitudes around drugs and to prevent substance misuse and related harm. Schools can reach large numbers of school-aged children, and programmes are easy to implement compared to family or community-based programmes. These prevention efforts in schools in Zambia, have been intensified since mid-1990s, that is, in terms of aggregate level of prevention activities, the number of organizations involved, and government's will to fight drug abuse in the country. Schools have implemented various prevention measures to ensure the health and safety of the learning environment.

However, despite considerable efforts directed towards prevention, the problem of drug and alcohol abuse among learners in Zambia's schools continued to rise. For example, a research conducted by the Zambia Global School Health Survey (2004) among learners in grades 7 to 10 in 47 schools in nine 
provinces, revealed that $42.6 \%$ of the 2, 257 learners who had participated, had taken alcohol on one or more occasions during the previous 30 days. Further evidence of the increased number of learners' involved in drug and alcohol use in schools is reflected by the Drug Enforcement Commission annual reports. For instance, in 2013, of the 288 persons attended to, 159 were learners and in 2014, of the 302 persons counselled, 176 were learners, while in 2015, 271 learners out of 415 persons were counselled for drug and alcohol abuse related problems(DEC, 2013., 2014 and 2015).This obviously demonstrated substantial increase in learners abusing drugs and alcohol.

The continued increase in the number of learners abusing drugs and alcohol in schools presents a challenge to its prevention and raises concerns about the kind of measures taken to prevent it. Can this be attributed to the kind of prevention policies being applied? There is little available information regarding the drug and alcohol abuse prevention policies used in schools to answer this question. It is against this gap in knowledge, that this study was undertaken. The article therefore, highlights policy guidelines used in drug and alcohol abuse prevention in secondary schools in Zambia.

\subsection{Statement of the Problem}

Policies are essential to the provision of effective and efficient prevention services. They provide guidance for prevention and management of drug and alcohol use in schools. In other words, they ensure the health and safety of the learning environment. Despite the escalating incidences of drug and alcohol abuse among learners, little was known concerning the nature of prevention policy guidelines used in Zambia's secondary schools. Therefore, it was necessary to conduct this study to establish policies used in drug and alcohol abuse prevention in selected secondary schools.

\subsection{Objective of the Study}

To establish drug and alcohol abuse prevention policy guidelines used in secondary schools.

\subsection{Research Questions}

What are the drug and alcohol abuse prevention policy guidelines used in secondary schools?

\subsection{Significance of the Study}

It is hoped that the findings from the study may help the Ministry of General Education in policy formulation as well as School administrators and teachers being prevention practitioners, to improve and implement effective drug and alcohol prevention policies in secondary schools in Zambia. It may also help schools to deal with drug abuse incidences in the learning environment by applying evidence-based procedures in order to enhance safety and health of learners. In the absence of specific and comprehensive policies on drug and alcohol abuse prevention in most, if not all schools, this study provides guidelines on some elements to be considered when developing a school drug policy. Furthermore, much of the research that has been conducted in Zambia concerning drug and alcohol abuse in schools is skewed to examining prevalence, determinants and consequences, therefore the current study would be a useful contribution to the body of knowledge on school-based drug and alcohol abuse prevention policy in Zambia.

\subsection{Study Sites}

The study was conducted in twenty (20) secondary schools located in five provinces namely; Lusaka, Copper belt, Southern, Eastern and Luapula. The provinces were chosen based on the prevalence rate of drug trafficking and abuse country-wide. According to Kusanthan (2014) prevalence of drug trafficking and abuse in Zambia is higher in Lusaka (87\%), followed by Copper belt (58\%), Eastern (44\%), Southern (34\%), Muchinga (33\%), Central (26\%) and North-western (20\%).

\subsection{Limitations of the Study}

Due to the sensitive nature of the study, it was difficult to collect information from some target groups. Some target groups did not want to present data which was considered 'damaging' to their school reputation, as a result, caution must be exercised when generalizing the results of the study. However, the researcher relied on triangulation to validate data.

\section{Methodology}

A descriptive survey design using both qualitative and quantitative methods was used to conduct this study. The design allowed the researcher to collect data, summarise, present and interpret it for the purpose of describing the policies used in secondary schools. (Ngesu, Ndika and Masese, 2008). 
In this study the population consisted of all learners in public secondary schools, teachers and head teachers in five provinces of Zambia namely; Lusaka, Copper belt, Southern, Eastern and Luapula. Others were all District Education Board Secretaries, and Drug Enforcement Commission officers in the selected sites.

A total number of five hundred and fourteen (514) respondents formed the sample. The break-down of respondents were as follows: four hundred (400) learners selected from twenty (20) secondary schools. This number of learners was chosen because it represented the recipients of drug and alcohol preventive education.Other respondents selected were ninety-one (91) teachers; twelve (12) head teachers and five (5) officers from the Drug Enforcement Commission. They were chosen because they represented providers or facilitators of drug and alcohol preventive education in schools. They had vast information on the subject and practical experience in conducting drug prevention activities. In addition, six (6) District Education Board Secretaries from ten districts namely; Lusaka, Chongwe, Ndola, Luanshya, Choma, Mazabuka, Chipata, Katete, Mansa and Samfya were also included. This number sufficiently represents influencers of school policy in the respective districts.

A multi-stage sampling was conducted in which both probability and non-probability procedures were employed. This involved sampling of provinces, districts, schools and finally respondents. For instance, purposive sampling for teachers, head teachers, DEBS and DEC officers, and simple random and systematic random sampling for learners.

Using questionnaires, quantitative data was collected from learners and teachers and analyzed using the Statistical Package for Social Sciences (SPSS) to generate tables, graphs and percentages. Semistructured interview and focus group discussion guides were used to collect qualitative data from Head Teachers, DEBS, DEC officers and learners, which was analyzed using thematic analysis. Thus, major themes were drawn for easy descriptions. Due to the sensitive nature of the subject, ethical precautions were taken in this study. This included explaining the purpose of the study thus giving respondents chance to decide on whether to participate in the study and by ensuring their anonymity.

\section{FINDINGS AND DisCUSSION}

The study sought to establish drug and alcohol abuse prevention policy guidelines used in secondary schools. The guiding question for this study was: "what are the drug and alcohol abuse prevention policy guidelines used in secondary schools? 'In answering this question, firstly, the researcher sought to find out whether secondary school had school drug prevention policies in place and in what form they were presented.Second, to establish the nature of policy guidelines applied. Data obtained through document analysis conducted to check on policy guidelines, viz-a- viz measures for dealing with violations of drug and alcohol abuse rules by learners were considered. Findings from learners, teachers, head teachers and DEBS, and documents analysed are presented in the three subsections below.

\subsection{Existence of School Drug and Alcohol Policy}

Concerning the existence of school drug and alcohol policy in schools, majority (94.3\%) of learners indicated that they had written rules and regulations in place. Details of the distribution of respondents are shown in table 1 below.

Table1. Whether there are rules or regulations on drug and alcohol abuse in the school

\begin{tabular}{|c|c|c|c|}
\hline \multicolumn{2}{|c|}{ Responses } & Frequency & Percent \\
\hline \multirow{4}{*}{} & Yes & 377 & 94.3 \\
\cline { 2 - 4 } & No & 8 & 2.0 \\
\cline { 2 - 4 } & Not sure & 12 & 3.0 \\
\cline { 2 - 4 } & No response & 3 & .8 \\
\cline { 2 - 4 } & Total & $\mathbf{4 0 0}$ & $\mathbf{1 0 0 . 0}$ \\
\hline
\end{tabular}

During focus group discussions, learners further confirmed the existence of school rules and regulation concerning drug and alcohol abuse prevention. One girl participant said:

"Yes we have school rules which stop us from drinking beer and smoking. Our class teacher read them out to us in class last term, when one of the learners was found drinking in town." 
Teachers, head teachers and DEBS agreed with learners on the existence of written rules and regulations. However, head teachers clarified that they did not have a separate and specific policy document on drug and alcohol use. The rules and regulations on drug and alcohol use by schools were enshrined in the school rules document.In trying to elaborate the point, one Head teacher said:

"My school does not have what you may consider as a school drug and alcohol policy per se. In addition, I think generally there is no school which has a policy specifically for drug issues. However, our school rules are meant to instill discipline among learners in a variety of areas. Yes there are some clauses which talk about the offences and punishment about drug and alcohol abuse. This is the document we use to deal with learners who are found in this situation."

This clarification clearly showed that there was lack of a specific document on drug prevention policy in the selected secondary schools. This finding is contrary to what is generally obtained in most parts of the developed world, as a study review conducted by Evans-Whipp et al (2004) shows that most schools in the developed countries have written drug and alcohol abuse prevention policies.School drug and alcohol abuse prevention policies are important because they inform practice and ultimately they form part of the broader drug and alcohol abuse prevention education strategy. Lack of comprehensive policy guidelines may contribute to non-achievement of prevention goals in the school.

\subsection{Major Drug and Alcohol Policy Guidelines used in Schools}

With regard to major elements of drug and alcohol abuse prevention policy guidelines, findings showed that out of 91teachers who participated in the study, $75.8 \%$ of them indicated statements on offences and measures for abrogation as the main elements that constituted school rules. Head teachers and DEBS also felt that the school rules relating to drug prevention were mainly concerned with offences and measures applied to deter the occurrence of the drug use behaviour. However, head teachers added that statements that addressed the general conduct of learners in school and in class were included. One head teacher said:

"For example our school rules indicate that any learner found smoking and drinking alcohol shall either be made to call their parents, suspended, punished heavily or expelled from school. There are other rules which generally talk about bullying and other forms of violence in the schools."

Further, an analysis of school rules documents revealed only one common statement which stood as a specific drug prevention related guideline in all documents. This was the statement which stipulated prohibition of smoking and beer drinking by learners and consequences for abrogating the rule. For example, in one document it read:

Smoking and drinking: No pupil should be involved in smoking, drinking liquor or any intoxicating drink and drug abuse. Penalties; severe punishment...

Another one read:

Drinking beer or any intoxicating substances, abuse of drug and smoking of any kind is strictly forbidden. Places associated with selling or consumption of intoxicants is out of bounds at all times. Penalty- suspension ...

This finding corroborated those of teachers, head teachers and DEBS. Hence, it is conclusive to say that the only major element that constitutes drug abuse prevention policy in the selected secondary schools were statements on offences and measures for abrogating school rules regarding drug and alcohol use or by learners. Indeed these findings only highlight one element of drug prevention policy guidelines. However, this is contrary to the recommendation by UNODC, 2004; Maine Office of Substance Abuse, 2008; Sloboda, 2008; and Catholic Education Office Melbourn, 2010, who indicated a host of key elements that included the following: A philosophical statement, rationale and goals to be achieved; prevention education programmes to be implemented; processes for communicating policy to learners, parents and the community and written procedures for dealing with drug abuse incidences in the school. Other elements are specification of substances targeted for prevention; identified specific support services and networks available to learners and lastly statements on prohibition and drug and alcohol abuse and consequences for violation. 


\subsection{Measures Taken Against Learners Found or Reported to be Abusing Drugs and Alcohol}

The researcher asked respondents to indicate how the school authority treated learners who abrogated drug and alcohol rules and regulations. This aspect was important because it helped to describe further, the nature of policy guidelines used. Both quantitative and qualitative data from learners revealed the following: summoning parents, suspension, expulsion, physical punishment, counselling, forced transfer and being reported to the police or the Drug Enforcement Commission, with summoning parents on top of the list. For example quantitative results showed that most, 301(24.1\%) of the 1, 251 respondents indicated summoning parents to school, followed by suspension at $298(23.8 \%)$ and expulsion at 218(17.4\%). Figure 1below, shows details of respondents.

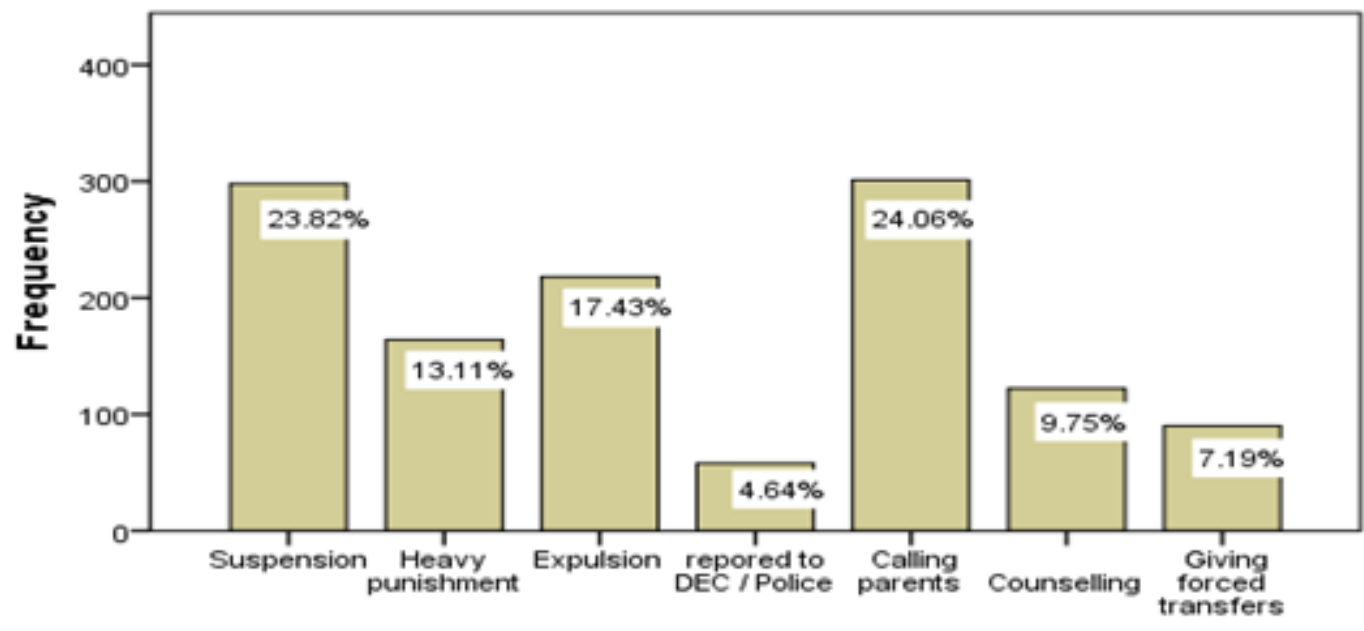

Figure1. Responses on measures taken by school authority to curb drug and alcohol abuse problem

Teachers indicated similar responses to those of learners with counselling as apriority measure. Similarly, findings from head teachers and DEBS emphasized on counselling, manual work (Physical punishment) and summoning parents as common measures. The researcher observed that most head teachers and DEBS avoided mentioning expulsion, while learners emphasized suspension, expulsion and forced transfer, as one head teacher lamented:

"The process of expelling a child is very long and not easy. In very rare circumstances do we resort to this measure."

The responses by head teachers may have been influenced by not wanting to be perceived as high handed administrators because suspension and expulsion measures are widely seen as negative and disadvantageous to learners.

An analysis of these findings show that the common measures used were mainly measures such as suspension, forced transfers physical punishment with counselling at the bottom of the list, while expulsion was used under extreme circumstances. From the findings, it is clear that these measures were punitive in nature aimed at not only punishing the offender but also to deter others from committing the same offence. Similar findings were reported by Beyers et al. (2005). They found that school drug policy measures in USA schools were generally more punitive in nature with suspension and expulsion as some of the common measures applied. The application of these measures entails taking away learning time from the learners and this consequently leads to resentment and further involvement in drug and alcohol abuse. As pointed out by Glisic (2010) such measures may not yield significant results in prevention efforts. Inherently the perceived lack of success in addressing the problem of drug and alcohol abuse among learners in secondary schools may be attributed to this situation.

The researcher is of the view that these findings, clearly demonstrate a big gap in policy direction that can address the problem in a secondary school set up. Firstly, the absence of a clearly stated and comprehensive policy document on drug and alcohol abuse may be the contributor to the current increase in drug and alcohol abuse among learners in schools. As rightly pointed out by Gaustad (1993:1) "learners whose schools lack clear alcohol and drug policies are more likely to use or experiment with chemical substances." Lack of specific and comprehensive drug and alcohol abuse 
prevention policy can seriously affect prevention efforts in secondary schools. Secondly, the kind of measures used to deal with drug and alcohol abuse infractions are punitive in nature than remedial or educational. Such measures may increase resentment by learners to adhere to policy guidelines and consequently affect policy implementation in the school. There is need for schools to have an appropriate policy for dealing with drug and alcohol abuse prevention.

\section{Conclusion And Recommendations}

This section provides the conclusions drawn from the research findings. In line with the study objective on the policy guidelines used in drug and alcohol abuse prevention education in the selected secondary schools, firstly, the researcher concludes that there was lack of specific documents on drug and alcohol prevention policy guidelines in all the secondary schools. Instead, drug and alcohol prevention policy guidelines used were enshrined in the general school rules. Secondly, the elements of drug prevention policy guidelines used were largely punitive in nature as opposed to educational or remedial.They mainly included statements of prohibitions and measures such as suspension, expulsion, heavy physical punishment and forced transfers. Such measures were meant to punish those learners who abrogated the rules. Based on the study findings, the following recommendations are made:

- Considering the continued increase of drug and alcohol abuse among school children, there is need for secondary schools to have an appropriate and specific drug and alcohol abuse prevention policy. The learner population in secondary schools is at an adolescent stage where guidance is inevitable. Lack of specific prevention policy in secondary schools to provide guidelines for learners' behaviour can seriously hamper prevention efforts to reduce abuse of drug and alcohol. The Ministry of General Education and District Education Boards in conjunction with school administrators could spearhead the introduction of school drug and alcohol policy in secondary schools.

- School policies aimed at preventing drug and alcohol abuse should focus more on educational and remedial measures rather than on punitive measures such as heavy physical punishment, suspension, expulsions and forced transfers, because the latter only aggravates the learners' situation in most circumstances. For instance, forced transfers is only a sure way of shifting problems to other schools as learners may become more rebellious and continue abusing drugs.

- School policy document on drug and alcohol abuse prevention should not only reflect statements on prohibition of drug and alcohol use and punishment for abrogation of rules but also a philosophical statement that expresses the rationale and goals it aims to achieve; a description of how the school will implement prevention programmes and activities; and an outline of the process for communicating the policy to learners, teachers, parents and community. Furthermore, it should indicate written procedures describing the steps to be taken when dealing with drug abuse incidents, and also a provision for periodic review of the policy (UNODC, 2004; Maine Office of Substance Abuse, 2008; Catholic Education Office Melbourne, 2010). Additionally, the review of policy should be conducted regularly.

\section{REFERENCES}

Beyers, J.M., Evans-Whipp, T.J., Mathers, M., Toumbourou J.W., and Catalano, R.F. (2005). A crossnational comparison of school drug policies in Washington State, United States and Victoria, Australia. J Sch health 75(14) pp134-40.

Botvin, G.J. (2006). Preventing Drug Abuse through the Schools: Intervention programmes that work in NIDA Conference on Drugs. (http://www.drugabuse.go/drugpage.html).

Catholic Education Office Melbourne (2010) Drug Issues in Catholic Schools. http://cevncecv. catholic.edu.au/cevnlogin

DEC, (2013), Annual Report

DEC, (2014), Annual Report

DEC, (2015), Annual Report

Dunne, C. \& Somerset, M. (2004). "Health promotion in university: what do students want?" Health Education, 104, 360-370.

Evans-Whipp, T.J, Beyers, J. M., Lloyd, S., Lafazia, A. N., Toumbourou, J. W., Arthur, M.W., \& Catalano, R. F. (2004). A review of school drug policies and their impact on youth substance use.Health Promotion International. 19(2), 227-234. 
Gaustad, J. (1993). Substance Abuse Policy, Eric Digest, Number 80. (www.eric.ed.gov)

Glisic, M. (2010). Effectiveness of school policies prohibiting adolescent alcohol and drug use. University of Toronto (Dissertation)

Kusanthan, T. (2014). Situation analysis of the extent of trafficking in abuse of illicit drugs and other substances in Zambia. Lusaka: Ministry of Home Affairs. (Unpublished).

Maine Office of Substance Abuse (2008). Your Substance Abuse Policy: A Comprehensive Guide for Schools

Ngesu, L.M., Ndiku, J. and Masese, A. (2008). "Drug Dependence and Abuse in Kenyan Secondary Schools: Strategies for Intervention” In Educational Research and Review Vol.3(10), pp. 304308.

Sloboda, Z. (2008), 'Moving towards evidence-based practice: school-based prevention of substance use in the USA', in: A Cannabis Reader: Global Issues and Local Experiences, Monograph Series 8, Vol.1, EMCDDA, Lisbon.

UNODC, (2004). Conducting effective substance abuse prevention work among the youth in South Africa. Regional office for southern Africa. www.unodc.org.za

Wyler, L.S. (2012) International Drug Control Policy: Background and US. Response, Congress Research Service. www.crs.gov

\section{AUTHORS' BIOGRAPHY}

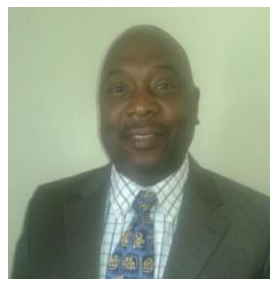

Isaac Masiye, is an Educational Psychologist and a PhD Candidate in the School of Education, Department of Educational Psychology, Sociology and Special Education (EPSSE) at the University of Zambia. He is currently serving as Deputy National Coordinator in the Education and Counselling Department of the Drug Enforcement Commission - Zambia. He has over 15 years' experience in the field of drug and substance abuse prevention education and counselling. His $\mathrm{PhD}$ thesis is about Drug and Alcohol Abuse Prevention Education Practices and Policies in Secondary schools in Zambia. He has published three articles on drug and alcohol abuse prevention in International Journals, the latest being in the International Journal of Humanities, Social Sciences and Education. (Online) ISSN 2349-0381; V. 3; I 9; September 2016, pp. 67-74. Isaac has also participated in various National and International fora on strategic planning of prevention programmes. He is currently the African Union Commission (AUC) - Drug Demand Reduction Focal point for Zambia.

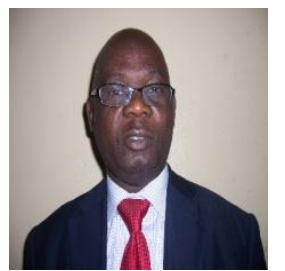

Dr. Daniel Ndhlovu, is a Senior lecturer in the Department of Educational Psychology, Sociology and Special Education at the University of Zambia. $\mathrm{He}$ holds a doctoral degree in Special Education, Master'sDegree in Education and Bachelor's degree in Special Education from the University of Zambia. In addition to lecturing, he has held senior administrative positions at the University of Zambia which includes Assistant Dean Postgraduate in the School of Education and Assistant Director Postgraduate in the Institute of Distance Education. Daniel has 29 years teaching and lecturing experience at secondary school, tertiary and university levels of education. He has done numerous research activities and publications in local and international refereed journals. His latest publication isDrug and Alcohol Abuse Prevention Education in Selected Secondary Schools in Zambia: Current Practices, by Isaac Masiye and Daniel Ndhlovu. International Journal of Humanities, Social Sciences and Education. Online ISSN 2349-0381; Volume 3; Issue 9; September 2016;pp.67-74. 